\title{
Use of therapeutic anticoagulation in splanchnic vein thrombosis associated with acute pancreatitis: a systematic review and meta- analysis
}

\author{
Saurabh Chandan ${ }^{a}$, Avanija Buddama, Shahab R. Khan ${ }^{b}$, Babu P. Mohanc, Daryl Ramaid, Mohammad Bilale, \\ Banreet Dhindsaf, Neil Bhogalf, Lena L. Kassab", Hemant Goyal' , Abhilash Perisetti', Antonio Facciorusso', \\ Douglas G. Adlerc \\ CHI Creighton University Medical Center, Omaha, Nebraska, USA; Harvard Medical School, Boston, Massachusetts, \\ USA; University of Utah School of Medicine, Salt Lake City, Utah, USA; Brooklyn Hospital Center, Brooklyn, \\ New York, USA; University of Minnesota \& Minneapolis VA Health Care System, Minneapolis, Minnesota, USA; \\ University of Nebraska Medical Center, Omaha, Nebraska, USA; Mayo Clinic, Rochester, Minnesota, USA; The Wright \\ Center For Graduate Medical Education, Scranton, Philadelphia, USA; University of Arkansas for Medical Sciences, \\ Little Rock, Arkansas, USA; University of Foggia, Foggia, Italy
}

\section{Abstract}

Conflict of Interest: Douglas G. Adler is a consultant at Boston Scientific. All other authors report no conflict of interest

Correspondence to: Douglas G. Adler MD, FACG, AGAF, FASGE, Professor of Medicine, Director of Therapeutic Endoscopy, Director, GI fellowship Program, Gastroenterology and Hepatology, University of Utah School of Medicine, Huntsman Cancer Center, 30N 1900E 4R118, USA, e-mail: dougraham2001@gmail.com

Received 22 February 2021; accepted 26 April 2021; published online 14 September 2021

DOI: https://doi.org/10.20524/aog.2021.0661

\begin{abstract}
Background Splanchnic vein thrombosis is a well-recognized local vascular complication of acute pancreatitis (AP), estimated to occur in approximately $15 \%$ of patients. While splanchnic vein recanalization occurs spontaneously in approximately one third of patients, severe complications such as bowel ischemia and liver failure have also been reported. At present, there is no consensus on whether patients presenting with AP-associated splanchnic vein thrombosis should receive therapeutic anticoagulation.
\end{abstract}

Methods We searched multiple databases from inception through December 2020 to collect stuch clinical outcomes of patients with AP and splanchnic vein thrombosis who therapeutic anticoagulation (AC group) with those who did not (N-AC group). A meta-analysis was performed to calculate the relative risk (RR) of vessel recanalization, bleeding Results Seven studies with 8353 patients, 339 of whom had splanchnic vein thrombosis, were included in the final analysis. A total of 154 patients (45.4\%) had acute severe pancreatitis. A significantly higher proportion of patients had vessel recanalization in the AC group: RR 1.6, $95 \%$ confidence interval $1.17-2.27 ; I^{2}=0 \% ; \mathrm{P}=0.004$. There was no difference between the 2 groups in the RR of bleeding complications, collateral formation and death.

Conclusions Our analysis demonstrated that, among patients with AP-associated splanchnic vein thrombosis, therapeutic anticoagulation resulted in recanalization of the involved vessels without significantly increasing the risk of bleeding complications. There was no difference in the RR of or the rates of collateral vessel formation during the follow up.

Ann Gastroenterol 2021; 34 (1): 1-14

\section{Introduction}

Acute pancreatitis (AP) is an inflammatory disorder of the pancreas associated with substantial morbidity and mortality. The global incidence of AP is 34 affected individuals per 100,000 person-years, and it has been increasing worldwide [1]. The worldwide obesity epidemic is also thought to be contributing to the overall increasing global incidence of AP [2]. While the morbidity and long-term sequelae of AP remain substantial, the associated mortality has seen a downward trend over the 
past decade, from $1.6 \%$ to $0.8 \%$, in part due to improvements in timely and accurate diagnosis, as well as in the care of critically ill patients with AP [3]. Despite this, AP is currently one of the most common gastrointestinal disorders warranting hospitalization in the United States and accounts for $\$ 9.3$ billion in healthcare costs annually [4].

Splanchnic vein thrombosis is a well-recognized local vascular complication of AP [5], estimated to occur in approximately $15 \%$ of patients [6]. Its etiology is thought to be due in part to the anatomic relationship of the large mesenteric vessels to the pancreas, the prothrombotic nature of the acute inflammatory reaction, along with contributions from systemic response to the injury, hypovolemia and fluid shifts [7]. Splanchnic vein thrombosis may involve thrombosis of the splenic vein (SpVT), portal vein (PVT) and superior mesenteric vein (SMVT), either separately or in combination, and is often detected incidentally on imaging performed to evaluate the symptoms and/or complications of AP. While splanchnic vein recanalization occurs spontaneously in approximately one third of patients $[8,9]$, severe complications such as bowel ischemia and liver failure have also been reported [10]. Additionally, progressive splanchnic vein thrombosis can result in portal hypertension with resulting complications, including hemorrhage [11].

At present, there is no consensus on whether patients presenting with splanchnic vein thrombosis in the setting of AP should receive therapeutic anticoagulation. We conducted a systematic review of the published literature and performed a meta-analysis to assess the safety and clinical outcomes of anticoagulation in AP-associated splanchnic vein thrombosis.

\section{Materials and methods}

\section{Search strategy}

The relevant medical literature was searched by a medical librarian for studies reporting outcomes of anticoagulation

${ }^{a}$ Division of Gastroenterology \& Hepatology, CHI Creighton University Medical Center, Omaha, Nebraska, USA (Saurabh Chandan, Avanija Buddam); ${ }^{b}$ Department of Medicine, Brigham \& Women's Hospital, Harvard Medical School, Boston, Massachusetts, USA (Shahab R. Khan); 'Division of Gastroenterology and Hepatology, University of Utah School of Medicine, Salt Lake City, Utah, USA (Babu P. Mohan, Douglas G. Adler); 'Internal Medicine, Brooklyn Hospital Center, Brooklyn, New York, USA (Daryl Ramai); 'Division of Gastroenterology, University of Minnesota \& Minneapolis VA Health Care System, Minneapolis, Minnesota, USA (Mohammad Bilal); ${ }^{\mathrm{f}}$ Gastroenterology \& Hepatology, University of Nebraska Medical Center, Omaha, Nebraska, USA (Banreet Dhindsa, Neil Bhogal); Internal Medicine, Mayo Clinic, Rochester, Minnesota,

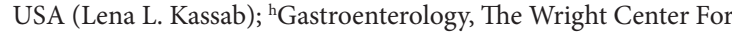
Graduate Medical Education, Scranton, Philadelphia, USA (Hemant Goyal); ${ }^{i}$ Gastroenterology \& Hepatology, University of Arkansas for Medical Sciences, Little Rock, Arkansas, USA (Abhilash Perisetti); ${ }^{j}$ Gastroenterology Unit, Department of Surgical and Medical Sciences, University of Foggia, Foggia, Italy (Antonio Facciorusso) in patients with splanchnic vein thrombosis in the setting of AP. The search strategy was created using a combination of keywords and standardized index terms. A systematic and detailed search was run in December 2020 in Ovid EBM Reviews, ClinicalTrials.gov, Ovid Embase (1974+), Ovid Medline (1946+ including Epub ahead of print, in-process \& other non-indexed citations), Scopus (1970+), and Web of Science (1975+). Results were limited to English language publications only.

The full search strategy is available in Supplementary Appendix 1. As the included studies were observational in design, the MOOSE (Meta-analyses Of Observational Studies in Epidemiology) checklist was followed [12] and is provided as Supplementary Appendix 2. The PRISMA flowchart for study selection [13] was followed and is provided as Supplementary Fig. 1. The reference lists of evaluated studies were examined to identify other studies of interest.

\section{Study selection}

We included studies that compared the clinical outcomes of patients with AP and splanchnic vein thrombosis who received therapeutic anticoagulation with those who did not. Studies included were cohort and case-control studies that reported outcomes of both treatment approaches. Studies were included whether they were published as full manuscripts or conference abstracts, were performed in an inpatient or outpatient setting, irrespectively of followup time and country of origin, as long as they provided the appropriate data needed for the analysis.

Our exclusion criteria were as follows: 1) case series and case reports; 2) studies in which patients received prophylactic anticoagulation; 3) studies including patients with chronic pancreatitis; 4) studies performed in the pediatric population (age <18 years); and 4) studies not published in English. In cases of multiple publications from a single research group reporting on the same patient, same cohort and/or overlapping cohorts, data from the most recent and/or most appropriate comprehensive report were retained. The remaining studies were evaluated by 2 authors (SC, DR) based on the publication timing (most recent) and/ or the sample size of the study (largest). In situations where a consensus could not be reached, overlapping studies were included in the final analysis and any potential effects were assessed in a sensitivity analysis of the pooled outcomes, leaving out one study at a time.

\section{Data abstraction and quality assessment}

Data on study-related outcomes from the individual studies were abstracted independently onto a standardized form by at least 2 authors (SC, SRK). Other authors (AP, BD, DR, NB) cross-verified the collected data for possible errors and 2 authors (SC, SRK) performed the quality scoring independently. We used the Newcastle-Ottawa scale to assess the quality of cohort 
studies [14]. This quality score consists of 8 questions, the details of which are provided in Supplementary Table 1.

\section{Outcomes assessed}

Patients were grouped based on whether they received anticoagulation $(\mathrm{AC})$ or not $(\mathrm{N}-\mathrm{AC})$. The primary outcomes assessed were the relative risk (RR) of vessel recanalization, bleeding complications, collateral formation and death in patients who received anticoagulation compared with those who did not. The secondary outcomes measured were the pooled rates of vessel recanalization, bleeding complications, collateral formation and death in patients who received anticoagulation and in patients who did not receive anticoagulation.

\section{Statistical analysis}

We used meta-analysis techniques to calculate the pooled estimates in each case, following the methods suggested by DerSimonian and Laird and using the random-effects model. Results were expressed in terms of RR or mean difference (MD) along with relevant 95\% confidence intervals (CI), when appropriate [15]. When the incidence of an outcome was zero in a study, a continuity correction of 0.5 was added to the number of incident cases before statistical analysis [16]. We assessed heterogeneity between study-specific estimates using the Cochran Q statistical test for heterogeneity, 95\%CI, and the $I^{2}$ statistics $[16,17]$, in which values of $<30 \%, 30$ $60 \%, 61-75 \%$, and $>75 \%$ were suggestive of low, moderate, substantial and considerable heterogeneity, respectively. We assessed publication bias, qualitatively, by visual inspection of funnel plot, and quantitatively, by the Egger test [18]. When publication bias was present, further statistics using the failsafe $\mathrm{N}$ test and Duval and Tweedie's "Trim and Fill” test was used to ascertain the impact of the bias [19]. Three levels of impact were reported, based on the concordance between the reported results and the actual estimate if there was no bias. The impact was reported as minimal if both versions were estimated to be same, modest if effect size changed substantially but the final finding would still remain the same, and severe if the basic final conclusion of the analysis was threatened by the bias [20]. A Knapp-Hartung 2-tailed P-value of $<0.05$ was considered statistically significant and the $\mathrm{R}^{2}$ value was calculated to study the goodness of fit. All analyses were performed using Comprehensive Meta-Analysis software, version 3 (BioStat, Englewood, NJ).

\section{Results}

\section{Characteristics and quality of included studies}

Seven studies with 8353 patients, 339 of whom had splanchnic vein thrombosis, were included in the final analysis. The severity of pancreatitis was defined as per the Atlanta Criteria [8,21], Revised Atlanta Classification [22-24] and Balthazar score [25]. Of 135 patients with splanchnic vein thrombosis reported in 5 studies [8,21-23,25], 78 (57.7\%) were classified as having severe AP. In another study, all 148 of the included patients were classified as having moderately severe or severe AP [24].

Six of the included studies were retrospective in design [8,9,23-26], while one was a prospective multicenter study [22]. Only one of the included studies was published in abstract form but presented pertinent outcomes of interest [26]. Two studies were performed in the USA, 4 in Europe and 1 in India. Based on the Newcastle-Ottawa scoring system, all included studies were considered to be of high quality.

\section{Search results and population characteristics}

Our initial search strategy yielded 67 results. All search results were exported to Endnote, where 26 obvious duplicates were removed leaving 41 citations. A schematic diagram demonstrating our study selection is presented in Supplementary Fig. 1.

All studies reported information on thrombus location: 26 patients had isolated PVT, 194 had isolated SpVT and 5 patients had isolated SMVT. A vast majority of patients had a combination of vessels involved. Details of patient characteristics and demographics were available in 5 studies. A total of 172 males and 91 females were included in our analysis, with mean age ranging from $36.6-58$ years. The follow-up period ranged from 3-24 months.

\section{Imaging modalities utilized for diagnosis and follow up of splanchnic vein thrombosis}

All studies used pancreas protocol contrast-enhanced computed tomography (CT), magnetic resonance imaging and/or color Doppler ultrasonography [8,9,22-25]. Splanchnic vein thrombosis was diagnosed when an actual thrombus was detected in the vein, or the vein appeared compressed, or was not visualized with presence of collaterals. Portal cavernoma was defined radiologically as the presence of large portoportal collaterals. Follow-up imaging, including contrast CT $[21,23,25]$ and Doppler ultrasonography [8], was done to assess for recanalization of involved vessels.

\section{Type and duration of anticoagulant agent used}

Four studies provided information on the type of therapeutic anticoagulation used. In 2 studies, therapeutic low-molecular-weight heparin (LMWH) $(1 \mathrm{mg} / \mathrm{kg}$ b.i.d.) or intravenous unfractionated heparin infusion (initial bolus of $80 \mathrm{U} / \mathrm{kg}$, followed by an initial infusion rate of $18 / \mathrm{kg} / \mathrm{h}$ ), 
according to the standard nomogram, was given. This was followed by maintenance therapy with warfarin to keep the international normalized ratio (INR) between 2 and $3[8,22]$. Gonzelez et al utilized the same anticoagulation protocol, but in that study the INR range was kept between 1.8 and 2 [9].

In another study, a therapeutic dose of LMWH was administered (100 UI/kg b.i.d.) to in-patients at the time of diagnosis and patients were subsequently fully anticoagulated upon discharge with fondaparinux $7.5 \mathrm{mg} /$ day, or vitamin $\mathrm{K}$ antagonist (warfarin) (target INR 2.0-3.0), or novel direct oral anticoagulants, [23]. Three studies did not provide information on the therapeutic modality used in the anticoagulated group [24-26]. Further details of patient characteristics and clinical outcomes are described in Tables 1 and 2 .

\section{Meta-analysis outcomes}

\section{Pooled RR and rates of vessel recanalization}

The pooled rate of vessel recanalization at follow up in the AC group (6 studies, 53 of 103 patients) was 51.5\%, 95\%CI $35.5-67.1 ; I^{2} 52 \%$, while in the N-AC group (5 studies, 40 of 136 patients) it was $28.6 \%, 95 \%$ CI $18.6-41.3 ; I^{2}=38 \%$. The difference between the 2 was statistically significant: RR 1.6, 95\%CI 1.17-2.27; $I^{2}=0 \%$; $\mathrm{P}=0.004$ (Fig. 1).

\section{Pooled RR and rates of bleeding complications}

The pooled rate of bleeding complications in the AC group was $21.2 \%, 95 \%$ CI $14-30.6 ; I^{2}=0 \%$, while in the $\mathrm{N}$-AC group it was $11 \%, 95 \%$ CI $6.5-17.9 ; I^{2}=0 \%$. The difference between the 2 was not statistically significant: RR 1.95 , 95\%CI 0.98-3.88; $I^{2}=0 \% ; \mathrm{P}=0.06$ (Fig. 2).

\section{Pooled RR and rates of collateral formation}

The pooled rate of collaterals formation in the AC group was $43.3 \%, 95 \%$ CI $26.1-62.3 ; I^{2}=61 \%$, while in the N-AC group it was $46.2 \%, 95 \%$ CI $31.3-61.8 ; I^{2}=26 \%$. The difference between the 2 was not statistically significant: RR $1.24,95 \%$ CI 0.75-2.05; $I^{2}=24 \% ; \mathrm{P}=0.4$ (Fig. 3).

\section{Pooled RR and rates of death}

The pooled death rate in the AC group was $12.6 \%, 95 \% \mathrm{CI}$ $7.5-20.4 ; I^{2}=0 \%$, while in the N-AC group it was $6.8 \%$, 95\%CI 3.5-12.8; $I^{2}=0 \%$. The difference between the 2 was not statistically significant: RR $2.02,95 \%$ CI $0.85-4.8 ; I^{2}=0 \%$; $=0.1$ (Fig. 4).

\section{Validation of meta-analysis results}

\section{Sensitivity analysis}

To assess whether any one study had a dominant effect on the meta-analysis, we excluded one study at a time and analyzed its effect on the main summary estimate. No one study had a dominant effect on our study outcomes.

\section{Heterogeneity}

We assessed dispersion of the calculated rates using the $I^{2}$ percentage values, as reported in the meta-analysis outcomes section. While there was moderate to substantial heterogeneity in the pooled rates of vessel recanalization and collateral formation in both groups, the pooled RR ratios between the 2 groups had zero to low heterogeneity.

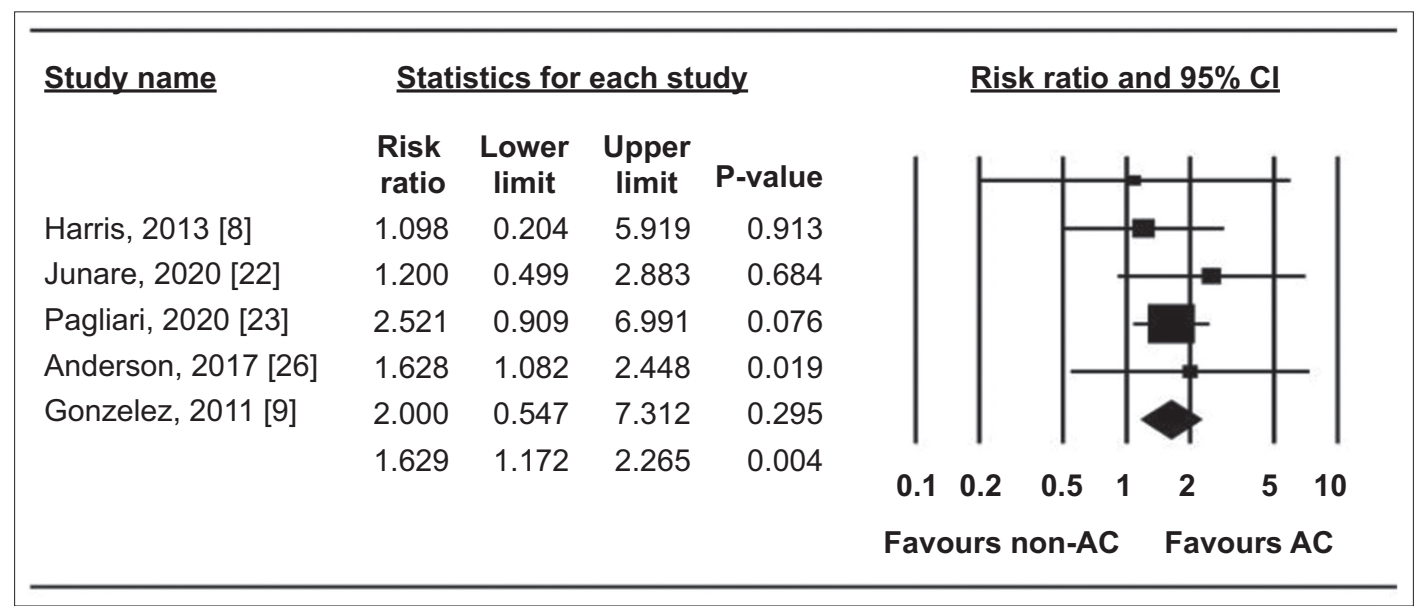

Figure 1 Forest plot, vessel recanalization 
Table 1 Study population characteristics

\begin{tabular}{|c|c|c|c|c|c|c|c|c|c|}
\hline \multirow{3}{*}{$\begin{array}{l}\text { Study } \\
\text { [Ref.] }\end{array}$} & \multirow[t]{3}{*}{ Design } & \multicolumn{2}{|c|}{ Total patients } & \multirow{3}{*}{$\begin{array}{l}\text { Age, } \\
\text { Mean } \\
\text { (SD) } \\
\text { [Range] }\end{array}$} & \multirow[t]{3}{*}{$\mathrm{M} / \mathrm{F}$} & \multirow{3}{*}{$\begin{array}{l}\text { Thrombus } \\
\text { location }\end{array}$} & \multirow{3}{*}{$\begin{array}{l}\text { Intervention } \\
\text { (heparin/ } \\
\text { coumadin/ } \\
\text { others) }\end{array}$} & \multicolumn{2}{|l|}{ Vessel involved } \\
\hline & & \multirow[t]{2}{*}{$\mathrm{AP}$} & \multirow[t]{2}{*}{$\begin{array}{l}\text { W / } \\
\text { thrombus }\end{array}$} & & & & & & \\
\hline & & & & & & & & $\mathrm{AC}$ & $\mathrm{N}-\mathrm{AC}$ \\
\hline $\begin{array}{l}\text { Harris, } \\
2013[8]\end{array}$ & $\begin{array}{l}\text { Retrospective, } \\
\text { Jan } 1996 \text { to } \\
\text { Dec 2006, } \\
\text { Single-center, } \\
\text { USA }\end{array}$ & 2454 & 45 & $58(15)$ & $31 / 14$ & $\begin{array}{l}\text { 7/45 (PVT), } \\
\text { 17/45 (SpVT), } \\
4 / 45 \text { (SMVT), } \\
4 / 45 \text { (SMVT + } \\
\text { PVT), 4/45 (PVT } \\
+ \text { SpVT), 4/45 } \\
\text { (SpVT + SMVT), } \\
5 / 45 \text { (SMVT + } \\
\text { PVT + SpVT) }\end{array}$ & $\begin{array}{l}17 \text { (heparin - } \\
\text { warfarin) }\end{array}$ & 11/17 (PVT) & $\begin{array}{l}22 / 28 \\
(\mathrm{SpVT})\end{array}$ \\
\hline $\begin{array}{l}\text { Junare, } \\
2020 \text { [22] }\end{array}$ & $\begin{array}{l}\text { Prospective, } \\
\text { Jan } 2018 \text { to } \\
\text { Dec 2018, } \\
\text { Multicenter } \\
\text { (02), India }\end{array}$ & 105 & 24 & $\begin{array}{l}36.62 \\
(6.49)\end{array}$ & $19 / 5$ & $\begin{array}{l}\text { 11/24 (SpVT), } \\
4 / 24(\mathrm{SpVT} \\
+\mathrm{PVT}), 9 / 24 \\
(\mathrm{SpVT}+\mathrm{PVT}+ \\
\text { SMVT) }\end{array}$ & $\begin{array}{l}12 \text { (heparin - } \\
\text { warfarin) }\end{array}$ & $\begin{array}{l}1 / 12(\mathrm{SpVT}) \\
2 / 12(\mathrm{SpVT} \\
+\mathrm{PV}), 9 / 12 \\
(\mathrm{SpVT}+\mathrm{PV} \\
+\mathrm{SMVT})\end{array}$ & $\begin{array}{l}10 / 12 \\
(\mathrm{SpVT}), \\
2 / 12(\mathrm{SpVT} \\
+\mathrm{PV}), 0 / 12 \\
\text { (SpVT + PV } \\
+ \text { SMVT) }\end{array}$ \\
\hline $\begin{array}{l}\text { Pagliari, } \\
2020 \text { [23] }\end{array}$ & $\begin{array}{l}\text { Retrospective, } \\
\text { Dec } 2015 \text { to } \\
\text { Dec } 2018, \\
\text { Single-center, } \\
\text { Italy }\end{array}$ & 221 & 27 & $\begin{array}{c}55.1 \\
(13.8) \\
{[25-79]}\end{array}$ & $23 / 4$ & $\begin{array}{l}\text { 9/27 (SpVT), } \\
10 / 27(\mathrm{SpVT}+ \\
\text { SMVT), } 1 / 27 \\
(\mathrm{PVT}), 2 / 27 \\
(\mathrm{SpVT}+\mathrm{PVT}), \\
1 / 27(\mathrm{PVT}+ \\
\mathrm{SMVT}), 4 / 27 \\
(\mathrm{PVT}+\mathrm{SMVT}+ \\
\text { SpVT) }\end{array}$ & $\begin{array}{l}16 \text { (LMWH) } \\
\text { [Inpatient] } \\
-7 \text { (VKA), } 5 \\
\text { (fondaparinux), } \\
4 \text { (apixaban) } \\
\text { [After } \\
\text { discharge] }\end{array}$ & NR & NR \\
\hline $\begin{array}{l}\text { Toque, } \\
2015 \text { [25] }\end{array}$ & $\begin{array}{l}\text { Retrospective, } \\
\text { Jan } 2007 \text { to } \\
\text { Dec } 2012 \text {, } \\
\text { Single-center, } \\
\text { France }\end{array}$ & 318 & 19 & $57(35)$ & $17 / 2$ & $\begin{array}{l}\text { 7/19 (SpVT), } \\
6 / 19(\mathrm{PVT}) \\
4 / 19(\mathrm{SpVT}+ \\
\text { SMVT), } 2 / 19 \\
(\mathrm{SpVT}+\mathrm{PVT}+ \\
\text { SMVT) }\end{array}$ & $\begin{array}{l}15 \text { (NR } \\
\text { - type of } \\
\text { anticoagulation } \\
\text { therapy) }\end{array}$ & NR & NR \\
\hline $\begin{array}{l}\text { Anderson, } \\
2017 \text { (abs) } \\
{[26]}\end{array}$ & $\begin{array}{l}\text { Retrospective, } \\
\text { Jan } 2007 \text { to } \\
\text { Jan } 2017 \text {, } \\
\text { Single-center, } \\
\text { USA }\end{array}$ & 4980 & 128 & $\begin{array}{c}51.4 \\
(13.7)\end{array}$ & $73 / 55$ & $\begin{array}{l}\text { 71/128 (PVT), } \\
80 / 128 \text { (SpVT), } \\
\text { 23/128 (PVT + } \\
\text { SpVT) }\end{array}$ & $\begin{array}{l}57 \text { (NR } \\
\text { - type of } \\
\text { anticoagulation } \\
\text { therapy) }\end{array}$ & NR & NR \\
\hline $\begin{array}{l}\text { Gonzelez, } \\
2011 \text { [9] }\end{array}$ & $\begin{array}{l}\text { Retrospective, } \\
\text { Jan } 2008 \text { to } \\
\text { Dec } 2009 \text {, } \\
\text { Single-center, } \\
\text { UK }\end{array}$ & 127 & 20 & $\begin{array}{c}53.5 \\
{[36-81]}\end{array}$ & $9 / 11$ & $\begin{array}{l}8 / 20(\mathrm{SpVT}), \\
5 / 20(\mathrm{PVT}), 1 / 20 \\
(\mathrm{SMVT}), 4 / 20 \\
(\mathrm{PVT}+\mathrm{SpVT}), \\
1 / 20(\mathrm{SpVT}, \\
\text { SMVT), } 1 / 20 \\
(\mathrm{PVT}+\mathrm{SpVT}+ \\
\text { SMVT) }\end{array}$ & $\begin{array}{l}4 \text { (LMWH) } \\
\text { [inpatient] } \\
\text { - } 4 \text { (VKA or } \\
\text { warfarin) [after } \\
\text { discharge] }\end{array}$ & $\begin{array}{l}2(\mathrm{PVT}), \\
2(\mathrm{PVT}+ \\
\text { SpVT) }\end{array}$ & $\begin{array}{l}8 \text { (SpVT), } \\
3 \text { (PVT), } 1 \\
(\text { SMVT), } \\
2 \text { (PVT } \\
+ \text { SpVT), } \\
1 \text { (SpVT, } \\
\text { SMVT), } \\
1 \text { (PVT + } \\
\text { SpVT + } \\
\text { SMVT) }\end{array}$ \\
\hline $\begin{array}{l}\text { Garret, } \\
2018[24]\end{array}$ & $\begin{array}{l}\text { Retrospective, } \\
\text { January } 2012 \\
\text { to December } \\
\text { 2015, Single- } \\
\text { center, France }\end{array}$ & 148 & 76 & NR & NR & SpVT 62/76 & NR & NR & NR \\
\hline
\end{tabular}

SD, standard deviation; $P V T$, portal vein thrombosis; SpVT, splenic vein thrombosis; SMVT, superior mesenteric vein thrombosis; NR, not reported; LMWH, low molecular weight heparin; VKA, vitamin K antagonist; AC, anticoagulation; AP, acute pancreatitis 
6 S. Chandan et al

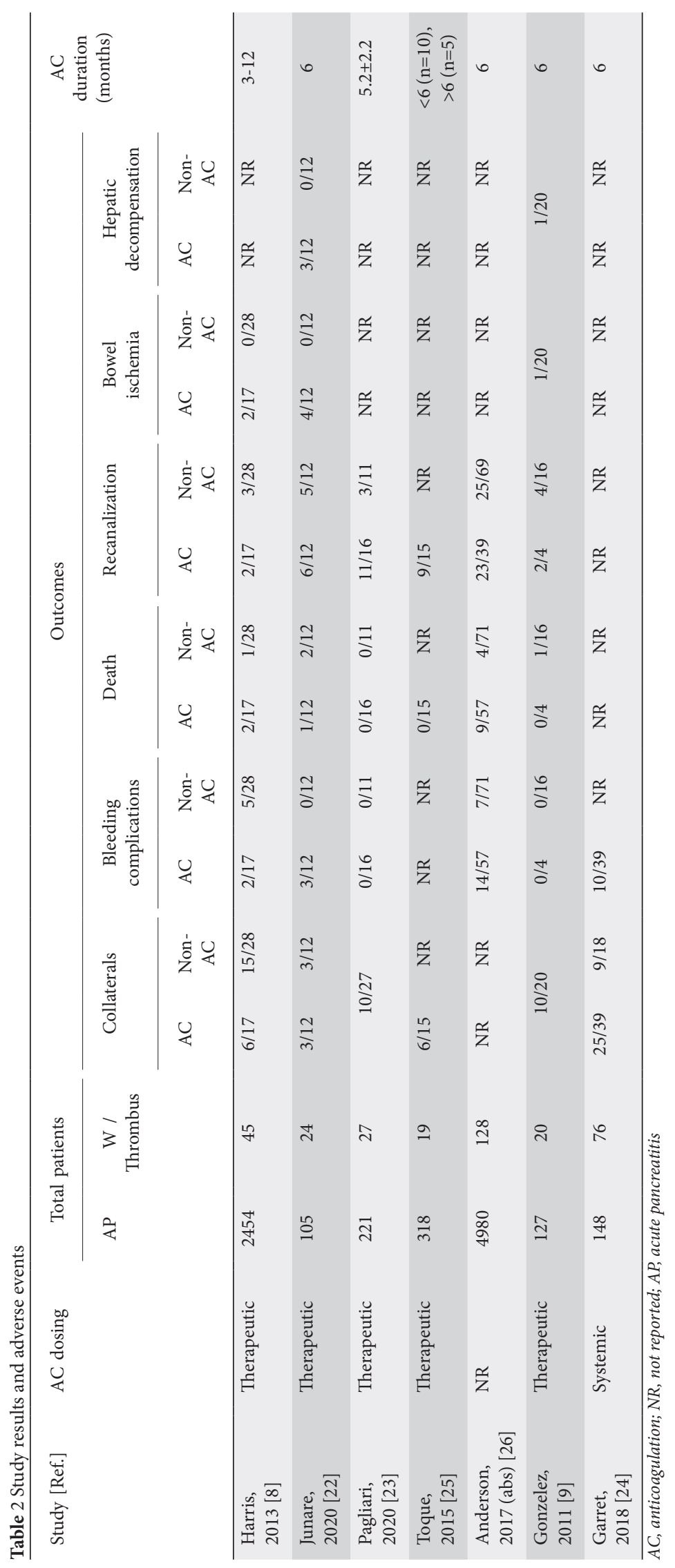




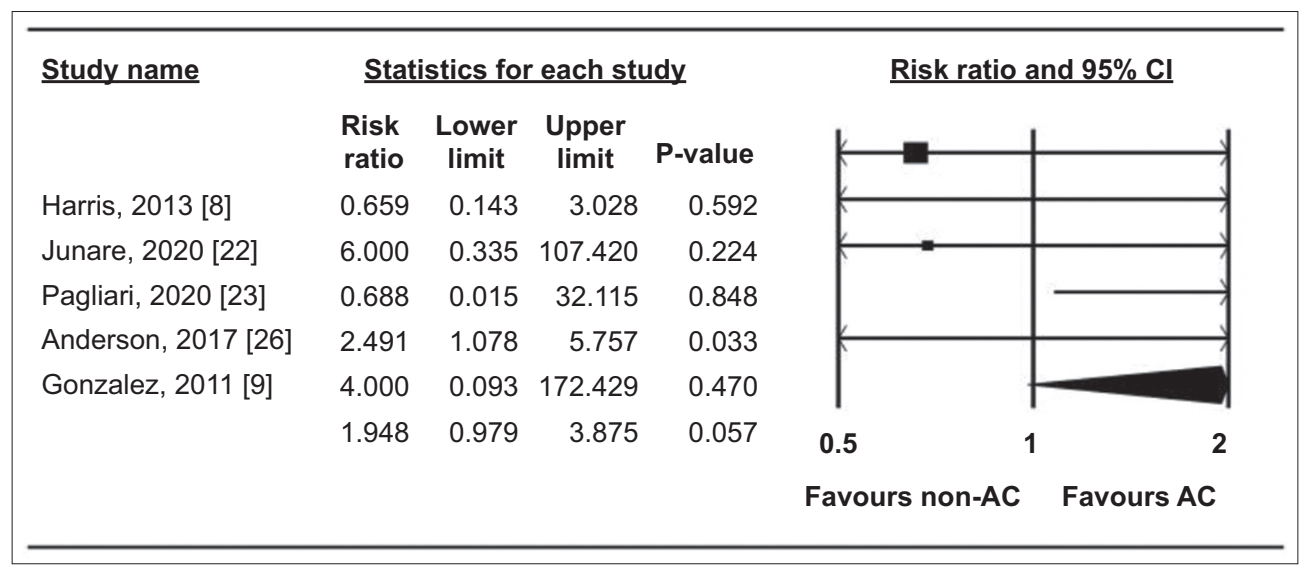

Figure 2 Forest plot, bleeding complications

\begin{tabular}{|c|c|c|c|c|c|}
\hline \multirow[t]{2}{*}{ Study name } & \multicolumn{4}{|c|}{ Statistics for each study } & Risk ratio and $95 \% \mathrm{Cl}$ \\
\hline & $\begin{array}{l}\text { Risk } \\
\text { ratio }\end{array}$ & $\begin{array}{c}\text { Lower } \\
\text { limit }\end{array}$ & $\begin{array}{l}\text { Upper } \\
\text { limit }\end{array}$ & P-value & $\mid$ \\
\hline Harris, 2013 [8] & 0.659 & 0.317 & 1.367 & 0.263 & \\
\hline Junare, 2020 [22] & 1.000 & 0.250 & 3.998 & 1.000 & - \\
\hline Pagliari, 2020 [23] & 2.491 & 1.078 & 5.757 & 0.033 & \\
\hline Anderson, 2017 [26] & 4.000 & 0.093 & 172.429 & 0.470 & \\
\hline \multirow[t]{3}{*}{ Gonzalez, 2011 [9] } & 1.282 & 0.764 & 2.153 & 0.347 & \\
\hline & 1.238 & 0.749 & 2.045 & 0.405 & $\begin{array}{lll}0.1 & 0.2 & 0.5\end{array}$ \\
\hline & & & & & Favours non-AC Favours AC \\
\hline
\end{tabular}

Figure 3 Forest plot, collateral formation

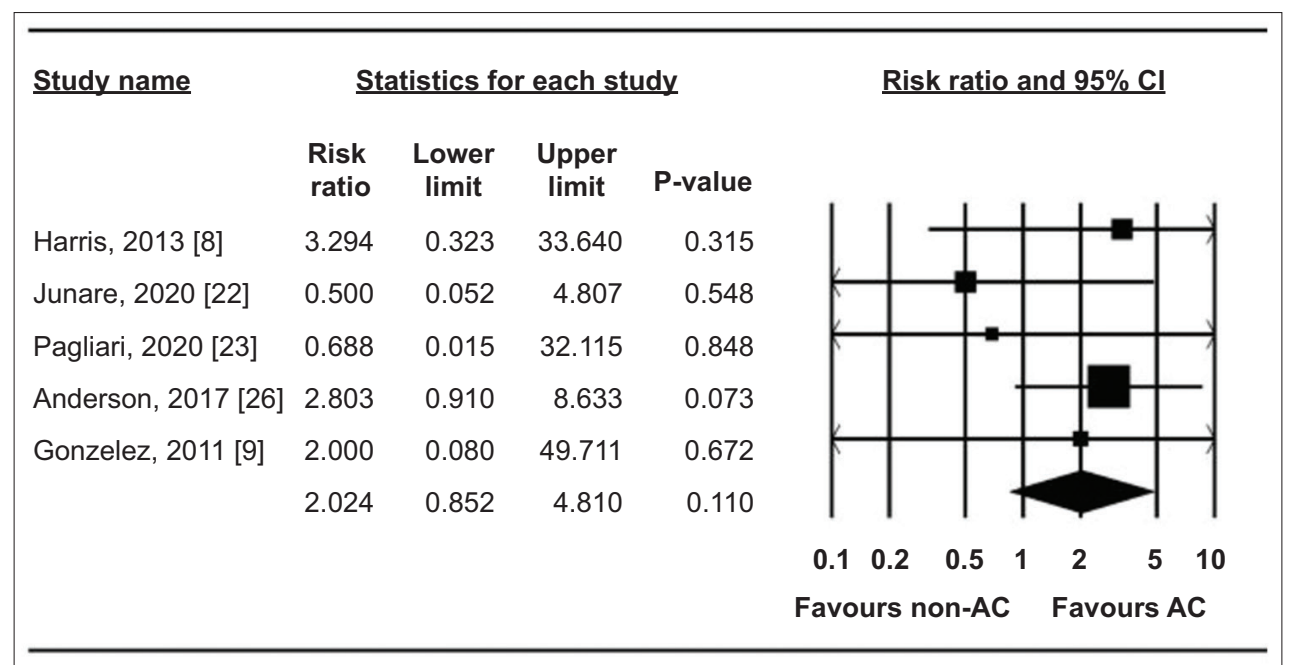

Figure 4 Forest plot, deaths 


\section{Publication bias}

Publication bias could not be estimated as the number of studies included our final analysis was less than 10 .

\section{Discussion}

Our analysis demonstrated that, among patients with AP found to have splanchnic vein thrombosis, therapeutic anticoagulation resulted in recanalization of the involved vessels without significantly increasing the risk of bleeding complications. We found no difference in the risk of death and rates of formation of collateral vessels at follow up between the $\mathrm{AC}$ and N-AC groups.

Splanchnic vein thrombosis is an increasingly recognized complication of AP. Its symptoms frequently overlap with those of AP and it is often diagnosed by imaging studies in the course of AP workup [27]. There is no consensus, however, with regard to anticoagulant treatment in these patients and whether it improves recanalization rates or overall clinical outcomes. Current society guidelines on AP do not specifically address this topic [28-30]. Timely intervention also needs to be considered, as splanchnic vein thrombosis may at times result in organ (bowel or hepatic) ischemia and necrosis if not recognized early [10,31]. Therefore, the risks and benefits of anticoagulation therapy in this subset of patients need to be thoroughly evaluated. Our results add to the current body of evidence on this challenging clinical scenario.

How does our study compare to the current published literature? A recent study by Zhou et al, including 273 patients with acute necrotizing pancreatitis, found that the application of timely systemic anticoagulation seems to reduce the incidence of splanchnic venous thrombosis and improves clinical outcomes without increasing the risk of hemorrhage. However, the percentage of patients developing recanalization or collateral circulation was not reported in this study [32]. Hajibandeh et $a l$, in a recent Letter to the Editor, concluded that current evidence suggests that the routine use of AC in the management of pancreatitis-induced splanchnic venous thrombosis does not provide any benefit over no $\mathrm{AC}$ and may increase the risk of bleeding. However, only 252 patients were included in the analysis that was the subject of the letter [33]. A previous systematic review and meta-analysis of 16 studies evaluated the safety and efficacy of anticoagulation for splanchnic vein thrombosis in patients with AP. The authors noted a $14 \%$ rate of recanalization in patients receiving anticoagulation, compared to $11 \%$ among those who did not. Bleeding complications were observed in $16 \%$ of patients receiving anticoagulation compared to $5 \%$ who did not. However, the analysis also included 9 individual case reports and 2 case series, leading to significant heterogeneity in the results, precluding the authors from performing a meta-analysis [34]. Additionally, cohort studies in which prophylactic, rather than therapeutic dosage of anticoagulation was administered, were included [35]. In our analysis we only included studies in which patients received therapeutic or systemic anticoagulation and there was no or low heterogeneity in our results.
There are several strengths to our review. First, our search strategy was meticulous, with well-defined inclusion criteria, careful exclusion of redundant studies, inclusion of good quality studies with detailed extraction of data, and rigorous evaluation of study quality. Second, we included only those studies where the outcomes of patients who received therapeutic anticoagulation were directly compared to those who did not. This allowed us to perform a robust meta-analysis of clinical and safety outcomes. Third, in all of the studies included in our analysis, splanchnic venous thrombus was diagnosed when an actual thrombus was detected in the vein, or the vein appeared compressed, or was not visualized with presence of collaterals.

There are several limitations to this study, most of which are inherent to any meta-analysis. First and foremost, the type of anticoagulant used and duration of therapy varied widely among the studies. The vessels involved were not equally distributed among the AC and N-AC groups in the included studies. In one study, some patients received AC for less than 6 months and others for longer [25]. Second, one of the included studies was only published in abstract format [26] and in another study not all our outcomes of primary interest were presented [24]. Two studies reported rates of collateral formation for the entire cohort of patients with splanchnic venous thrombosis, not for AC and N-AC groups separately [23,9]. Limited literature suggests that the rate of spontaneous recanalization may be as high as $30 \%$ in patients with SpVT [36]. While 10-year recurrence-free survival is highest for isolated $\mathrm{SpVT}$, this may not be true in patients with PVT and/or SMVT $[37,38]$. We were also unable to calculate the pooled outcomes of bowel ischemia and hepatic decompensation between the 2 groups, as this information was lacking in the studies. Third, 6 of the 7 studies included in our analysis were retrospective in design, while the severity classification criteria for AP varied across studies, which may have resulted in potential bias. Finally, a major concern for anticoagulation in splanchnic vein thrombosis is the risk of bleeding. While our analysis did not show a statistically significant difference in bleeding rates between the 2 groups, there was a trend towards more bleeding in patients receiving anticoagulation. Additionally, we did not report the etiology and severity of bleeding in our analysis, since this was not included in most studies. Further studies are warranted to stratify the risk of bleeding in patients with severe and non-severe AP receiving AC.

Despite these limitations, our study showed that the use of anticoagulation in patients with splanchnic vein thrombosis in the setting of AP resulted in higher rates of vessel recanalization, without an associated higher risk of bleeding complications. Our findings suggest that anticoagulation should be considered in AP patients with splanchnic vein thrombosis if there are no contraindications to anticoagulation.

\section{Acknowledgment}

The authors would like to thank Dana Gerberi, MLIS, Librarian, Mayo Clinic Libraries, for help with the systematic literature search 


\section{Summary Box}

\section{What is already known:}

- Splanchnic vein thrombosis is a well-recognized local vascular complication of acute pancreatitis (AP) and is estimated to occur in approximately $15 \%$ of patients

- While splanchnic vein recanalization occurs spontaneously in approximately one third of patients, severe complications such as bowel ischemia and liver failure have also been reported

- At present, there is no consensus on whether patients presenting with splanchnic vein thrombosis in the setting of AP should receive therapeutic anticoagulation

\section{What the new finding is:}

- Based on this meta-analysis, in patients with AP found to have splanchnic vein thrombosis, therapeutic anticoagulation resulted in recanalization of the involved vessels without significantly increasing the risk of bleeding complications

\section{References}

1. Petrov MS, Yadav D. Global epidemiology and holistic prevention of pancreatitis. Nat Rev Gastroenterol Hepatol 2019;16:175-184.

2. NCD Risk Factor Collaboration (NCD-RisC). Worldwide trends in body-mass index, underweight, overweight, and obesity from 1975 to 2016: a pooled analysis of 2416 population-based measurement studies in 128.9 million children, adolescents, and adults. Lancet 2017;390:2627-2642.

3. Krishna SG, Kamboj AK, Hart PA, Hinton A, Conwell DL. The changing epidemiology of acute pancreatitis hospitalizations: a decade of trends and the impact of chronic pancreatitis. Pancreas 2017;46:482-488.

4. Peery AF, Crockett SD, Murphy CC, et al. Burden and cost of gastrointestinal, liver, and pancreatic diseases in the United States: update 2018. Gastroenterology 2019;156:254-272.

5. Rebours V, Boudaoud L, Vullierme MP, et al. Extrahepatic portal venous system thrombosis in recurrent acute and chronic alcoholic pancreatitis is caused by local inflammation and not thrombophilia. Am J Gastroenterol 2012;107:1579-1585.

6. Richards ER, Kabir SI, McNaught CE, MacFie J. Effect of thoracic epidural anaesthesia on splanchnic blood flow. Br J Surg 2013;100:316-321.

7. Ahmed SU, Rana SS, Ahluwalia J, et al. Role of thrombophilia in splanchnic venous thrombosis in acute pancreatitis. Ann Gastroenterol 2018;31:371-378.

8. Harris S, Nadkarni NA, Naina HV, Vege SS. Splanchnic vein thrombosis in acute pancreatitis: a single-center experience. Pancreas 2013;42:1251-1254.

9. Gonzelez HJ, Sahay SJ, Samadi B, Davidson BR, Rahman SH. Splanchnic vein thrombosis in severe acute pancreatitis: a 2 -year, single-institution experience. НРВ (Oxford) 2011;13:860-864.

10. Mallick IH, Winslet MC. Vascular complications of pancreatitis. JOP 2004;5:328-337.

11. Gotto A, Lieberman M, Pochapin M. Gastric variceal bleeding due to pancreatitis-induced splenic vein thrombosis. BMJ Case Rep 2014;2014:bcr2013201359.

12. Stroup DF, Berlin JA, Morton SC, et al. Meta-analysis of observational studies in epidemiology: a proposal for reporting. Meta-analysis Of Observational Studies in Epidemiology (MOOSE) group. JAMA 2000;283:2008-2012.

13. Moher D, Liberati A, Tetzlaff J, Altman DG; PRISMA Group. Preferred reporting items for systematic reviews and metaanalyses: the PRISMA statement. Ann Intern Med 2009;151:264269, W64.

14. Stang A. Critical evaluation of the Newcastle-Ottawa scale for the assessment of the quality of nonrandomized studies in metaanalyses. Eur J Epidemiol 2010;25:603-605.

15. DerSimonian R, Laird N. Meta-analysis in clinical trials. Control Clin Trials 1986; 7:177-188.

16. Sutton AJ AK, Jones DR, et al. Methods for meta-analysis in medical research. John Wiley and Sons, Ltd.; 2000.

17. Mohan BP, Adler DG. Heterogeneity in systematic review and meta-analysis: how to read between the numbers. Gastrointest Endosc 2019;89:902-903.

18. Higgins JP, Thompson SG, Deeks JJ, Altman DG. Measuring inconsistency in meta-analyses. BMJ 2003;327:557-560.

19. Duval S, Tweedie R. Trim and fill: A simple funnel-plot-based method of testing and adjusting for publication bias in metaanalysis. Biometrics 2000;56:455-463.

20. Rothstein HR, Sutton AJ, Borenstein M. Publication bias in metaanalysis: prevention, assessment and adjustments. John Wiley \& Sons, Ltd.; 2006.

21. Gonzalez HD, Sahay SJ, John J, Davidson BR, Rahman SH. Splanchnic vein thrombosis in severe acute pancreatitis - is systemic anticoagulation indicated? Pancreatology 2011;11:314. [Abstract]

22. Junare AR, Udgirkar S, Nair S, et al. Splanchnic venous thrombosis in acute pancreatitis: does anticoagulation affect outcome? Gastroenterology Res 2020;13:25-31.

23. Pagliari D, Cianci R, Brizi MG, et al. Anticoagulant therapy in the treatment of splanchnic vein thrombosis associated to acute pancreatitis: a 3-year single-centre experience. Intern Emerg Med 2020;15:1021-1029.

24. Garret C, Péron M, Reignier J, et al. Risk factors and outcomes of infected pancreatic necrosis: Retrospective cohort of 148 patients admitted to the ICU for acute pancreatitis. United European Gastroenterol J 2018;6:910-918.

25. Toqué L, Hamy A, Hamel JF, et al. Predictive factors of splanchnic vein thrombosis in acute pancreatitis: A 6-year single-center experience. J Dig Dis 2015;16:734-740.

26. Anderson W, Niccum B, Chitnavis M, Uppal D, Hays RA. Outcomes of anticoagulation for portal and/or splenic vein thrombosis in setting of acute pancreatitis. Am J Gastroenterol 2017;112:S6.

27. Valla D. Splanchnic vein thrombosis. Semin Thromb Hemost 2015;41:494-502.

28. Crockett SD, Wani S, Gardner TB, Falck-Ytter Y, Barkun AN; American Gastroenterological Association Institute Clinical Guidelines Committee. American Gastroenterological Association Institute Guideline on Initial Management of Acute Pancreatitis. Gastroenterology 2018;154:1096-1101.

29. Samarasekera E, Mahammed S, Carlisle S, Charnley R; Guideline Committee. Pancreatitis: summary of NICE guidance. BMJ 2018;362:k3443.

30. Leppäniemi A, Tolonen M, Tarasconi A, et al. Executive summary: WSES Guidelines for the management of severe acute pancreatitis. 
J Trauma Acute Care Surg 2020;88:888-890.

31. Mendelson RM, Anderson J, Marshall M, Ramsay D. Vascular complications of pancreatitis. ANZ J Surg 2005;75:1073-1079.

32. Zhou J, Zhang H, Mao W, et al. Efficacy and safety of early systemic anticoagulation for preventing splanchnic thrombosis in acute necrotizing pancreatitis. Pancreas 2020;49:1220-1224.

33. Hajibandeh S, Agrawal S, Irwin C, Obeidallah R, Subar D. Anticoagulation versus no anticoagulation for splanchnic venous thrombosis secondary to acute pancreatitis: do we really need to treat the incidental findings? Pancreas 2020;49:e84-e85.

34. Norton W, Lazaraviciute G, Ramsay G, Kreis I, Ahmed I, Bekheit M. Current practice of anticoagulant in the treatment of splanchnic vein thrombosis secondary to acute pancreatitis. Hepatobiliary
Pancreat Dis Int 2020;19:116-121.

35. Easler J, Muddana V, Furlan A, et al. Portosplenomesenteric venous thrombosis in patients with acute pancreatitis is associated with pancreatic necrosis and usually has a benign course. Clin Gastroenterol Hepatol 2014;12:854-862.

36. Nadkarni NA, Khanna S, Vege SS. Splanchnic venous thrombosis and pancreatitis. Pancreas 2013;42:924-931.

37. Thatipelli MR, McBane RD, Hodge DO, Wysokinski WE. Survival and recurrence in patients with splanchnic vein thromboses. Clin Gastroenterol Hepatol 2010;8:200-205.

38. Besselink MG. Splanchnic vein thrombosis complicating severe acute pancreatitis. HPB (Oxford) 2011;13:831-832. 


\section{Supplementary material}

\section{Appendix 1 Literature search strategy}

All EBM Reviews via Ovid (Cochrane Database of Systematic Reviews (2005+), ACP Journal Club (1991+), Cochrane Central Register of Controlled Trials (CCTR, 1991+), Cochrane Clinical Answers (CCA), Cochrane Methodology Register (2012+), Database of Abstracts of Reviews of Effects (DARE, 2016+), Health Technology Assessment Database (HTA, 2016+), National Health Service Economic Evaluation Databases (NHSEED, 2016+)):

acute-pancreatitis.ab,hw,ti. AND splanchnic.ab,hw,ti. AND (thrombo ${ }^{\star}$ or phlebothrombo $\left.{ }^{\star}\right) \cdot$ ab,hw,ti. AND ((anticoagula* or anti-coagula* or antithromb ${ }^{\star}$ or anti-thromb ${ }^{\star}$ or heparin* or LMWH or coumadin* or warfarin*).ab,hw,ti. or (anisindione or apolate-sodium or beciparcil or blood-clottinginhibitor* ${ }^{*}$ or chlorophacinone or coumarin or defibrotide or dextran-sulfate or diphenadione or fluindione or ghilanten or glycerophosphoinositol-inositolphosphodiesterase or glycosaminoglycan-polysulfate or iliparcil or inclacumab or mopidamol or naroparcil or phenindione or tecarfarin or torapsel or tretoquinol or uproleselan).ab,kw,ti.)

Embase via Ovid (1974+): ((acute pancreatitis/or acutepancreatitis.ab,kw,od,ti.) AND (splanchnic blood flow/ or splanchnic.ab,kw,od,ti.) AND (exp vein thrombosis/ or (thrombo* or phlebothrombo*).ab,kw,od,ti.) AND (anticoagulation/or exp anticoagulant agent/or (anticoagula* or anti-coagula* or antithromb ${ }^{\star}$ or anti-thromb ${ }^{\star}$ or heparin ${ }^{\star}$ or LMWH or coumadin* or warfarin $\left.{ }^{\star}\right) \cdot a b, k w, o d, t i, d u, t n$. or (anisindione or apolate-sodium or beciparcil or blood-clottinginhibitor* or chlorophacinone or coumarin or defibrotide or dextran-sulfate or diphenadione or fluindione or ghilanten or glycerophosphoinositol-inositolphosphodiesterase or glycosaminoglycan-polysulfate or iliparcil or inclacumab or mopidamol or naroparcil or phenindione or tecarfarin or torapsel or tretoquinol or uproleselan).ab,du,kw,od,ti,tn.) NOT (exp juvenile/not adult/, exp animal/not exp human/, case report/, case-report.ti.) Limit to English

MEDLINE via Ovid (1946+ and Epub Ahead of Print, In-Process \& Other Non-Indexed Citations and Ovid
MEDLINE(R) Daily): ((exp Pancreatitis/or acute-pancreatitis. ab,kw,ti.) AND (exp Splanchnic Circulation/or splanchnic. ab,kw,ti.) AND (exp Venous Thrombosis/or (thrombo* or phlebothrombo*).ab,kw,ti.) AND (exp Anticoagulants/ or (anticoagula* or anti-coagula* or antithromb ${ }^{*}$ or antithromb ${ }^{\star}$ or heparin* or LMWH or coumadin* or warfarin ${ }^{\star}$ ). $\mathrm{ab}, \mathrm{kw}, \mathrm{nm}$,ti. or (anisindione or apolate-sodium or beciparcil or blood-clotting-inhibitor ${ }^{\star}$ or chlorophacinone or coumarin or defibrotide or dextran-sulfate or diphenadione or fluindione or ghilanten orglycerophosphoinositol-inositolphosphodiesterase or glycosaminoglycan-polysulfate or iliparcil or inclacumab or mopidamol or naroparcil or phenindione or tecarfarin or torapsel or tretoquinol or uproleselan).ab,kw,ti,nm.) NOT (exp CHILD/not exp ADULT/, exp Animals/not Humans/, Case Reports/, case-report.ti.) Limit to English

Scopus via Elsevier (1970+): ((TITLE-ABS-KEY (acutepancreatitis) AND TITLE-ABS-KEY (splanchnic) AND TITLE-ABS-KEY (thrombo* OR phlebothrombo*))) AND (TITLE-ABS-KEY (anticoagula* OR anti-coagula* OR antithromb* OR anti-thromb* OR heparin* OR lmwh OR coumadin* OR warfarin* OR anisindione OR apolatesodium OR beciparcil OR blood-clotting-inhibitor ${ }^{*}$ OR chlorophacinone OR coumarin OR defibrotide OR dextransulfate OR diphenadione OR fluindione OR ghilanten OR glycerophosphoinositol-inositolphosphodiesterase OR glycosaminoglycan-polysulfate OR iliparcil OR inclacumab OR mopidamol OR naroparcil OR phenindione OR tecarfarin OR torapsel OR tretoquinol OR uproleselan)) AND (LIMIT-TO (LANGUAGE, "English"))

Web of Science Core Collection via Clarivate Analytics (1975+): TOPIC: (acute-pancreatitis) AND TOPIC: (splanchnic) AND TOPIC: (thrombo* or phlebothrombo*) AND TOPIC $=\left(\right.$ anticoagula ${ }^{*}$ or anti-coagula ${ }^{\star}$ or antithromb ${ }^{*}$ or anti-thromb ${ }^{\star}$ or heparin* or LMWH or coumadin* or warfarin $^{\star}$ or anisindione or apolate-sodium or beciparcil or blood-clotting-inhibitor* or chlorophacinone or coumarin or defibrotide or dextran-sulfate or diphenadione or fluindione or ghilanten orglycerophosphoinositol-inositolphosphodiesterase or glycosaminoglycan-polysulfate or iliparcil or inclacumab or mopidamol or naroparcil or phenindione or tecarfarin or torapsel or tretoquinol or uproleselan) Limit to English 


\begin{tabular}{|c|c|c|}
\hline Item No & Recommendation & $\begin{array}{c}\text { Reported on Page } \\
\text { No }\end{array}$ \\
\hline \multicolumn{3}{|c|}{ Reporting of background should include } \\
\hline 1 & Problem definition & 5 \\
\hline 2 & Hypothesis statement & 5 \\
\hline 3 & Description of study outcome(s) & 6 \\
\hline 4 & Type of exposure or intervention used & 6 \\
\hline 5 & Type of study designs used & 6 \\
\hline 6 & Study population & $6-7$ \\
\hline \multicolumn{3}{|c|}{ Reporting of search strategy should include } \\
\hline 7 & Qualifications of searchers (eg, librarians and investigators) & 6 \\
\hline 8 & Search strategy, including time period included in the synthesis and key words & $6-7$ \\
\hline 9 & Effort to include all available studies, including contact with authors & 7 \\
\hline 10 & Databases and registries searched & 6 \\
\hline 11 & Search software used, name and version, including special features used (eg, explosion) & 9 \\
\hline 12 & Use of hand searching (eg, reference lists of obtained articles) & 5 \\
\hline 13 & List of citations located and those excluded, including justification & $\begin{array}{c}7, \\
\text { Suppl App } 3\end{array}$ \\
\hline 14 & Method of addressing articles published in languages other than English & - \\
\hline 15 & Method of handling abstracts and unpublished studies & 6 \\
\hline 16 & Description of any contact with authors & - \\
\hline \multicolumn{3}{|c|}{ Reporting of methods should include } \\
\hline 17 & Description of relevance or appropriateness of studies assembled for assessing the hypothesis to be tested & 7 \\
\hline 18 & Rationale for the selection and coding of data (eg, sound clinical principles or convenience) & 7 \\
\hline 19 & Documentation of how data were classified and coded (eg, multiple raters, blinding and interrater reliability) & 7 \\
\hline 20 & Assessment of confounding (eg, comparability of cases and controls in studies where appropriate) & 7 \\
\hline 21 & $\begin{array}{l}\text { Assessment of study quality, including blinding of quality assessors, stratification or regression on possible } \\
\text { predictors of study results }\end{array}$ & 7 \\
\hline 22 & Assessment of heterogeneity & 9 \\
\hline 23 & $\begin{array}{l}\text { Description of statistical methods (eg, complete description of fixed or random effects models, justification } \\
\text { of whether the chosen models account for predictors of study results, dose-response models, or cumulative } \\
\text { meta-analysis) in sufficient detail to be replicated }\end{array}$ & $8-9$ \\
\hline 24 & Provision of appropriate tables and graphics & Tables 1-2, Figs 1-4 \\
\hline \multicolumn{3}{|c|}{ Reporting of results should include } \\
\hline 25 & Graphic summarizing individual study estimates and overall estimate & Figs 1-4 \\
\hline 26 & Table giving descriptive information for each study included & Table 1,2 \\
\hline 27 & Results of sensitivity testing (eg, subgroup analysis) & 12 \\
\hline 28 & Indication of statistical uncertainty of findings & $11-12$ \\
\hline
\end{tabular}


Appendix 3 (A) PRISMA Flowchart

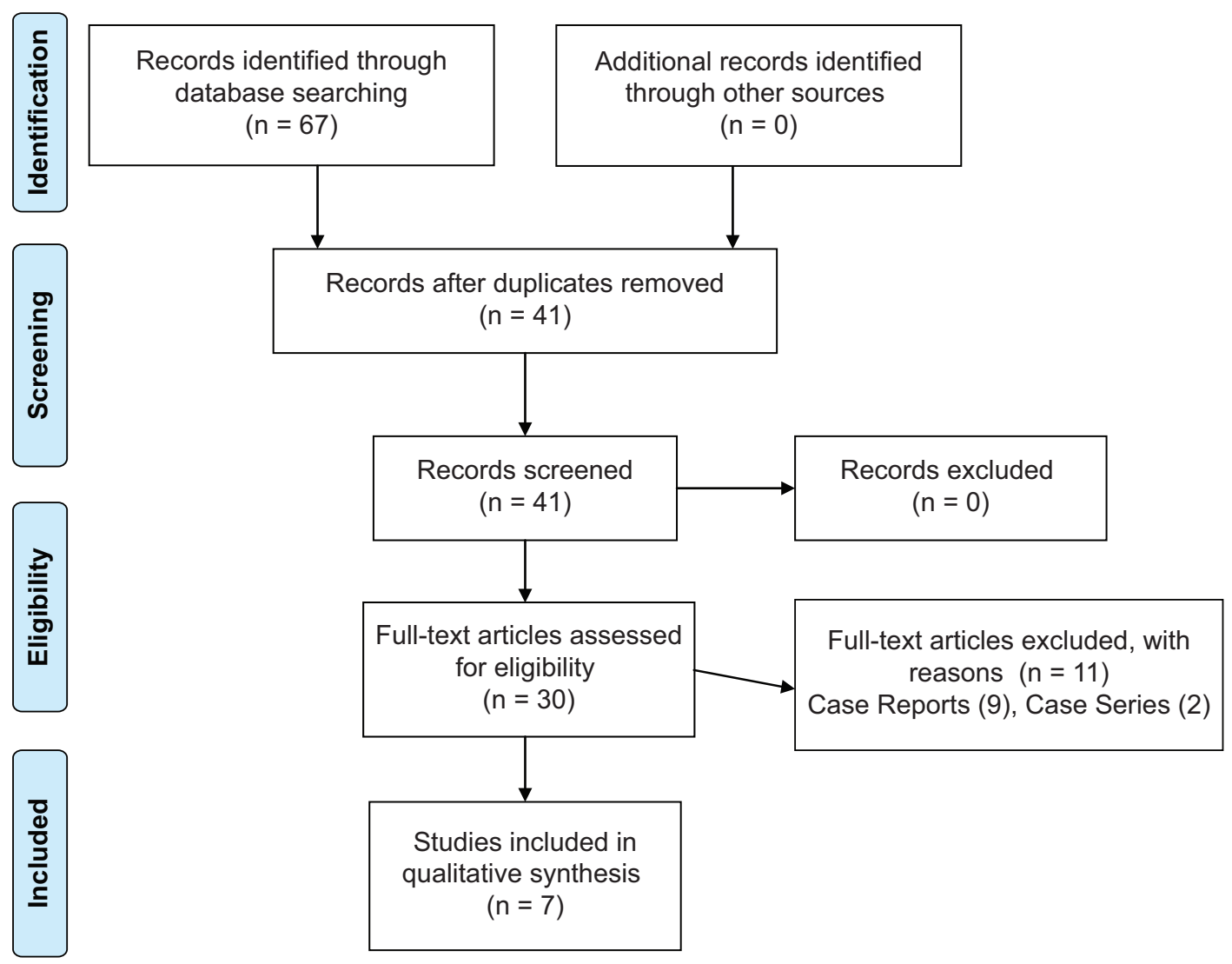


Appendix 3 (B) PRISMA Checklist

\begin{tabular}{|c|c|c|c|}
\hline Section/topic & $\#$ & Checklist item & Reported on page \# \\
\hline \multicolumn{4}{|c|}{ TITLE } \\
\hline Title & 1 & Identify the report as a systematic review, meta-analysis, or both. & 1 \\
\hline \multicolumn{4}{|c|}{ ABSTRACT } \\
\hline Structured summary & 2 & $\begin{array}{l}\text { Provide a structured summary including, as applicable: background; objectives; } \\
\text { data sources; study eligibility criteria, participants, and interventions; study } \\
\text { appraisal and synthesis methods; results; limitations; conclusions and } \\
\text { implications of key findings; systematic review registration number. }\end{array}$ & 4 \\
\hline \multicolumn{4}{|c|}{ INTRODUCTION } \\
\hline Rationale & 3 & Describe the rationale for the review in the context of what is already known. & $5-6$ \\
\hline Objectives & 4 & $\begin{array}{l}\text { Provide an explicit statement of questions being addressed with reference to } \\
\text { participants, interventions, comparisons, outcomes, and study design (PICOS). }\end{array}$ & $7-8$ \\
\hline \multicolumn{4}{|c|}{ METHODS } \\
\hline Protocol and registration & 5 & $\begin{array}{l}\text { Indicate if a review protocol exists, if and where it can be accessed (e.g., Web } \\
\text { address), and, if available, provide registration information including registration } \\
\text { number. }\end{array}$ & NA \\
\hline Eligibility criteria & 6 & $\begin{array}{l}\text { Specify study characteristics (e.g., PICOS, length of follow-up) and report } \\
\text { characteristics (e.g., years considered, language, publication status) used as } \\
\text { criteria for eligibility, giving rationale. }\end{array}$ & 7 \\
\hline Information sources & 7 & $\begin{array}{l}\text { Describe all information sources (e.g., databases with dates of coverage, contact with } \\
\text { study authors to identify additional studies) in the search and date last searched. }\end{array}$ & 6 \\
\hline Search & 8 & $\begin{array}{l}\text { Present full electronic search strategy for at least one database, including any } \\
\text { limits used, such that it could be repeated. }\end{array}$ & $\begin{array}{c}\text { 6-7 } \\
\text { Suppl Appx } 1\end{array}$ \\
\hline Study selection & 9 & $\begin{array}{l}\text { State the process for selecting studies (i.e., screening, eligibility, included in } \\
\text { systematic review, and, if applicable, included in the meta-analysis). }\end{array}$ & 7 \\
\hline Data collection process & 10 & $\begin{array}{l}\text { Describe method of data extraction from reports (e.g., piloted forms, } \\
\text { independently, in duplicate) and any processes for obtaining and confirming data } \\
\text { from investigators. }\end{array}$ & 8 \\
\hline Data items & 11 & $\begin{array}{l}\text { List and define all variables for which data were sought (e.g., PICOS, funding } \\
\text { sources) and any assumptions and simplifications made. }\end{array}$ & $8-9$ \\
\hline $\begin{array}{l}\text { Risk of bias in individual } \\
\text { studies }\end{array}$ & 12 & $\begin{array}{l}\text { Describe methods used for assessing risk of bias of individual studies (including } \\
\text { specification of whether this was done at the study or outcome level), and how } \\
\text { this information is to be used in any data synthesis. }\end{array}$ & 12 \\
\hline Summary measures & 13 & State the principal summary measures (e.g., risk ratio, difference in means). & $8-9$ \\
\hline Synthesis of results & 14 & $\begin{array}{l}\text { Describe the methods of handling data and combining results of studies, if done, } \\
\left.\text { including measures of consistency (e.g., } \mathrm{I}^{2}\right) \text { for each meta-analysis. }\end{array}$ & $10-11$ \\
\hline
\end{tabular}




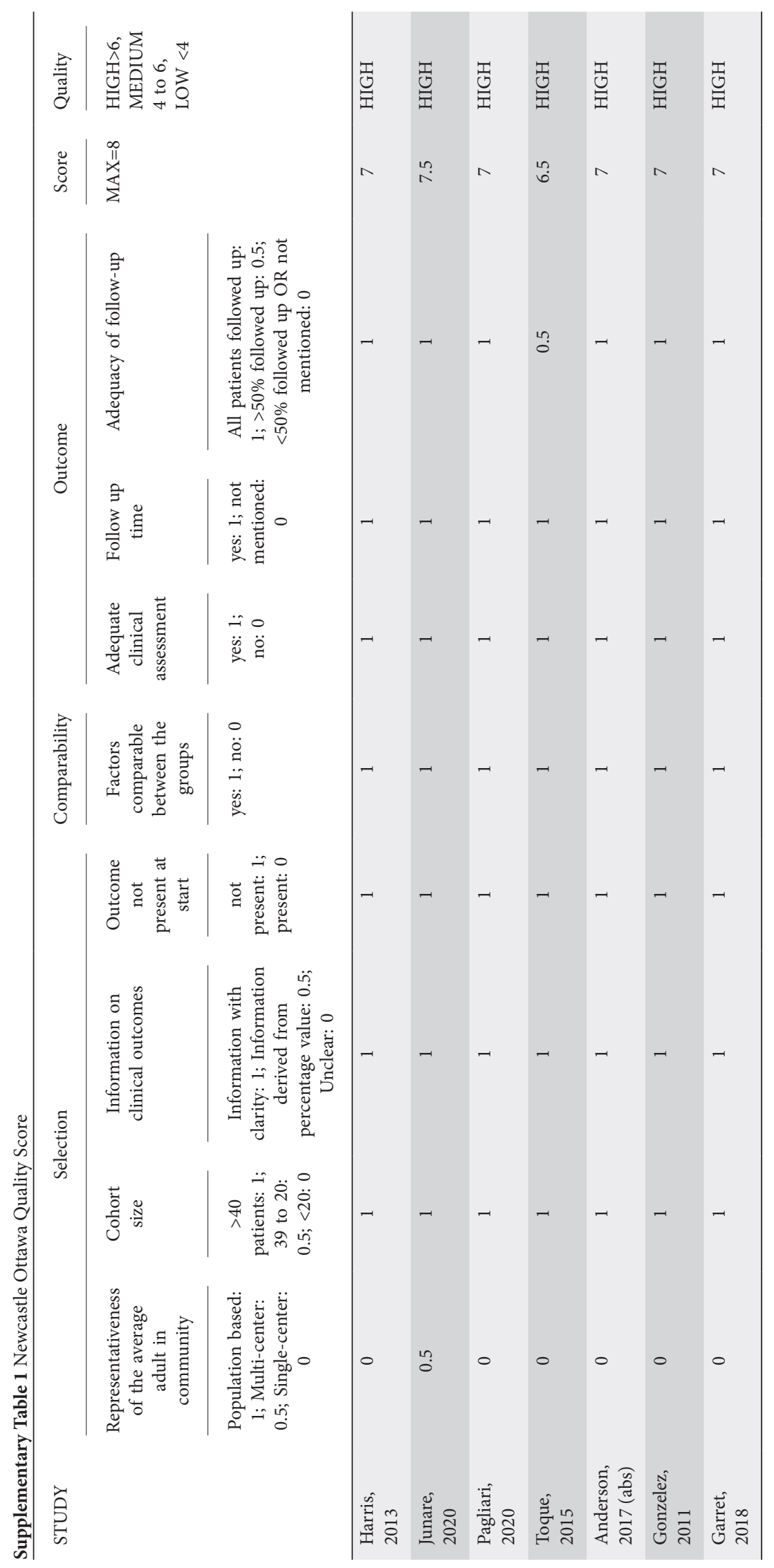

